FLUSSER, V. O mundo codificado: Por uma filosofia do design e da comunicação. São

Paulo: Cosac \& Naif, 2013.

\title{
A FILOSOFIA DA COMUNICAÇÃO DE FLUSSER OU POR UMA NOVA IMAGINAÇÃO
}

\author{
Larissa Drigo Agostinho ${ }^{1}$
}

O mundo codificado é uma coletânea de artigos publicados em um longo espaço de tempo, entre a década de 1970 e os anos 2000. Eles apresentam, como o título indica, a filosofia do design e da comunicação de Flusser.

O livro é divido em três partes: coisas, códigos, construções. A primeira parte é dedicada à definição do objeto de suas análises, destacando uma situação histórica no interior da qual a noção de coisa se transforma em "não-coisa" e, assim, demanda uma nova teoria da comunicação, adaptada a um objeto cuja fluidez se tornou inquestionável. Na segunda parte do livro, vem a apresentação da filosofia da comunicação de Flusser, baseada no conceito de código. Na terceira parte, "construções", vemos de que maneira Flusser concebe o design.

A tese de Flusser (2013: 127) é que a revolução na comunicação alterou completamente nossas vidas. Os códigos são o centro teórico desta revolução que o autor pretende pensar em toda a sua radicalidade, reflexão que o levará a defender uma nova imaginação. Para compreendermos de que maneira uma nova imaginação tornou-se necessária, partiremos, como sugere a coletânea, do conceito de coisa, de matéria.

Flusser (2013: 24) pretende recuperar um conceito, "hoje muito distorcido" de "imaterial". Ele distingue num primeiro momento matéria e forma. A matéria, do grego hylé, designa a madeira estocada nas oficinas dos carpinteiros. Ela se distingue da forma que a madeira pode tomar quando trabalhada pelo carpinteiro. Hylé designa, portanto a matéria amorfa. A matéria é o estofo que preenche a forma. Mas, podemos conceber a matéria como "um preenchimento transitório de formas atemporais?” (FLUSSER, 2013: 24). Essa definição não manteria a distinção entre a forma, como imutável e eterna e a

${ }^{1}$ Professora do Programa de pós-graduação da Pontifícia Universidade Católica PUC-SP e de Filosofia na ESPM. É bacharel em letras português/ francês pela Universidade de São Paulo, mestre em filosofia pela Universidade de Paris I Panthéon Sorbonne, mestre em literatura francesa e doutora pela Universidade de Paris IV-Sorbonne. Professora do Programa de pós-graduação da Pontifícia Universidade Católica PUCSP. E-mail: larissa_drigo@yahoo.com.br 
A filosofia da comunicação de Flusser ou por uma nova imaginação

de Larissa Drigo Agostinho

matéria como fluída e efêmera, mantendo, portanto, a distinção entre matéria e espírito, que tem como consequência o isolamento da matéria e da técnica (inclusive a arte) a um domínio perecível e indigno das Ideias?

Para sair deste impasse, Flusser estabelece uma distinção entre modos de pensar e ver que implicam em dois modos distintos de projetar: o material e oformal. O material cria representações. O carpinteiro, por exemplo, dá forma a matéria ao transformá-la em uma mesa. A "mesa" é uma ideia universal e abstrata que se incarna em materiais. No entanto, esse processo no qual a matéria é informada pode tanto corromper a ideia quanto alterar a matéria enformada.

Hoje, pensamos mais formalmente. Não se trata de distinguir uma forma, ou ideia, real, de uma mera aparência (matéria enformada), mas de definir o que é conveniente, ou a relação construtiva entre forma e matéria. "Em suma: as formas não são descobertas nem invenções, não são ideias platônicas nem ficções; são recipientes construídos especialmente para os fenômenos." (FLUSSER, 2013: 28).

Desta maneira, o pensamento formal não enfatiza aquilo que se vê na forma, como o pensamento material, mas a forma daquilo que vê, operando por modelos, como por exemplo, os canais de irrigação nas tábuas da Mesopotâmia, que organizam a cidade e a vida social ao projetar uma cidade e seus sistemas de irrigação. Se o pensamento material opera por funções, normas e regras reproduzindo parâmetros, o formal expõe a forma do que é visto, porque a forma é um modelo que se projeta no mundo e transforma o que toca. O que está em questão aqui, portanto, não é decidir se as imagens são superfícies da matéria, ou conteúdos de campos eletromagnéticos, mas distinguir se elas correspondem ao modo de pensar formal ou material. O critério, portanto, que permite distinguir as imagens hoje, o critério para a crítica da informação seria o seguinte: "Até que ponto as informações são operacionais ou produtivas?" Ou seja, não se trata de distinguir matéria e forma pela sua natureza material ou imaterial, corporal ou incorporal, sólida ou líquida, as imagens, a informação, o design, seus modelos e criações devem ser pensados a partir da sua própria produtividade, a partir do que são capazes de criar ou produzir. Esse seria o critério para a crítica da informação, segundo Flusser.

No interior deste aparato teórico que Flusser constrói, a comunicação é tida como um processo artificial que se serve de símbolos (artifícios, descobertas, ferramentas e instrumentos) organizados em códigos. Esses códigos se transformam em uma segunda natureza que nos faz "esquecer" a primeira, o mundo "em que somos condenados à morte" (FLUSSER, 2013: 90). Comunicação é ação do homem, por isso, ela pertence às ciências 
A filosofia da comunicação de Flusser ou por uma nova imaginação

de Larissa Drigo Agostinho

do espírito e requer um posicionamento particular do pesquisador. Não será questão aqui de explicar a comunicação, mas de interpretá-la. A teoria da comunicação de Flusser é uma disciplina interpretativa, no interior do qual a comunicação humana é abordada como um fenômeno a ser interpretado. A comunicação é um fenômeno, não uma "coisa em si”, ele se manifesta numa observação. Deve ser interpretada não objetivamente, mas intersubjetivamente. O ponto de vista de Flusser, "humanístico", entende a comunicação como um fenômeno de liberdade, assim a questão que se coloca é a de saber como ela é produzida e como deve ser armazenada.

Para produzir informação, os homens trocam diferentes informações disponíveis na esperança de sintetizar uma nova informação. Essa é a forma da comunicação dialógica. Para preservar, manter a informação, os homens compartilham informações existentes na esperança de que elas, assim compartilhadas, possam resistir melhor ao efeito entrópico da natureza. Essa é a forma de comunicação discursiva (FLUSSER, 2013: 97).

Essas duas formas são interdependentes e a diferença que as separa depende da "distância" da observação. Um diálogo surge porque informações foram colhidas de discursos anteriores. E todo discurso é composto por informações produzidas em um diálogo anterior. Cada discurso pode ser considerado parte de um diálogo e um diálogo é entendido como uma série de discursos orientados para a troca.

A dificuldade que enfrentamos hoje em dia, de produzir diálogos efetivos, para Flusser (2013, p. 98), se deve ao "funcionamento tão perfeito da comunicação, a saber, deve ser dirigida para a onipresença dos discursos predominantes, que tornaram todo diálogo impossível e ao mesmo tempo desnecessário." Flusser salienta aqui a importância da criação e da invenção na comunicação, para que os códigos não sejam apenas mecanismos de reprodução da normatividade em vigor na vida social. O diálogo sintetiza informações e produz novas informações. Mas, a nova informação só pode ser criada se houver um equilíbrio entre discurso e diálogo. Esse método, ou essa distinção, é ainda muito grosseira. O discurso e o diálogo possuem e atravessam meios distintos de comunicação, gêneros comunicativos distintos. Podemos distinguir mensagem a partir de seu conteúdo, semanticamente, ou a partir de sua "estrutura", sintaticamente.

Flusser entende que as análises sintáticas, estruturais, preparam o campo para futuras análises semânticas. Além disso, as análises sintáticas oferecem "mapas da situação comunicológica" no interior dos quais os sentidos podem ser inscritos. Nesta obra, o autor pretende apresentar um catálogo, um mapa das formas de comunicação. 
A filosofia da comunicação de Flusser ou por uma nova imaginação

de Larissa Drigo Agostinho

Evidentemente forma e conteúdo são inseparáveis, mas o foco central, o objetivo de Flusser (2013, p. 100) é traçar "um mapa de nossa condição."

Neste mundo invadido por imagens imateriais, a classe trabalhadora, operária é minoria em grande parte da Europa, a "moral burguesa baseada nas coisas - produção, acumulação e consumo -cede lugar a uma nova moral.” (FLUSSER, 2013: 55). É neste sentido que podemos falar em crise de valores, essa crise indica uma transformação no modo de produção no interior do capitalismo. "O mundo codificado em que vivemos não mais significa processos, vir-a-ser; ele não conta histórias e viver nele não significa agir. O fato de ele não significar mais isso é chamado de "crise de valores"” (FLUSSER, 2013: 135). Vivemos uma "volatização da consciência histórica", essa é a definição da ideologia dominante. E o papel do crítico diante desta crise é a "desideologização" (FLUSSER, 2013: 150)

A crise de valores é, portanto, associada à perda da consciência histórica, a uma crise da escrita. A história surge com a escrita, não porque a escrita nos permite conservar ou reviver o passado, mas porque passamos a experimentar o tempo historicamente, como um processo. A diferença entre a história e a pré-história é que na história os homens vêm, pensam e sentem o mundo como um acontecimento, um devir.

Flusser também estabelece uma distinção entre o mundo mítico, mágico, "imaginado", ou pré-histórico, onde o mesmo sempre retorna e o mundo da história, em que o tempo é o tempo da escrita, segue suas linhas e estabelece relações unívocas de uma corrente entre os elementos que compõe o texto. O mundo é linear, existem relações causais e temporais entre momentos e coisas, o tempo transcorre inevitavelmente do passado para o futuro e não há repetição.

É neste quadro que podemos compreender o conceito de imagem. A imagem possui uma dialética interna que explica a razão pela qual a escrita foi inventada, ou qual seria a sua função. As imagens podem tanto explicar o mundo como encobri-lo. Este mundo imaginário pode aprisionar o homem. A história e a escrita existem para nos permitir escapar desta "imaginação alucinatória". Assim "o propósito de escrever é explicar as imagens e a tarefa da razão é criticar a imaginação.” (FLUSSER, 2013: 149)

A radicalidade da crítica de Flusser às imagens e à imaginação se explica porque, para Flusser (2013: 146-149), podemos distinguir o mundo do futuro da pré-história quando pensamos os novos tipos de imagens que nos assombram, as "tecnoimagens" e a convenção na qual se baseiam, a tecnoimaginação. As tecnoimagens são imagens, e significam, como toda imagem, um mundo de mitos e de magia, mas essas novas imagens 
A filosofia da comunicação de Flusser ou por uma nova imaginação

de Larissa Drigo Agostinho

são míticas e mágicas num sentido muito distinto da pré-história: “as imagens préhistóricas representam o mundo, as imagens pós-históricas representam textos; a imaginação pré-histórica tenta agarrar o mundo, a imaginação pós-histórica tenta ser a ilustração de um texto." Enquanto os mitos pré-históricos designam situações "reais", as tecnoimagens são "prescrições textuais", pura ideologia, na pré-história os mitos visam propiciar o mundo, as tecnoimagens "manipular pessoas". Assim, "a tarefa da escrita hoje é explicar tecnoimagens e a tarefa da razão é criticar a tecnoimaginação.”

\section{CONCLUSÃO}

A comunicação nada contra a corrente, contra a "tendência cega da natureza para situações cada vez mais prováveis, para as cinzas” (Flusser, 2013: 94). Afirmações tão dogmáticas sobre o conceito de natureza devem chamar a atenção de alguns de nossos contemporâneos. É "vaga" a posição em que Flusser se coloca ao defender que a comunicação visa extrair o homem da solidão de seu estado natural, fazê-lo esquecer de sua condição de mortal. Uma evidência tão banal não pode fundamentar uma filosofia do design ou da comunicação. Afinal, não seria mais interessante pensarmos que a função da comunicação é organizar a vida social? Que ela faz parte de um conjunto de códigos sociais, normas, leis, valores, que ela alimenta, ao mesmo tempo que deles se nutre? Flusser propõe justamente pensar a comunicação como reprodução e invenção de novas relações e vínculos sociais, pois quando dialógica, a comunicação sintetiza, produz novas informações. E o papel do crítico da informação e da comunicação é pensar a produtividade e a natureza do que as imagens são capazes de produzir.

O conceito de imagem é por sua vez construído a partir de uma dicotomia que pode facilmente ser colocada em questão, a distinção entre história e pós-história. No entanto, se a distinção entre as formas de comunicação discursiva e dialógica, ganha novos contornos com a divisão da análise em semântica e sintática, porque permite que Flusser construa uma crítica da comunicação que não se reduz a moral, mas se baseia em formas concretas, a distinção entre pensamento formal e material permite distinguir dois tipos de imagens, as que reproduzem ou representam o que lhes cerca, e as que tornam visível uma forma, aplicam uma função, se desdobram em um novo modo de organizar o pensamento e o sensível.

Eis o que Flusser visa propor para que possamos escapar do fim da história, uma nova imaginação. As imagens representativas são funcionais ou instrumentais, são 
A filosofia da comunicação de Flusser ou por uma nova imaginação

de Larissa Drigo Agostinho

produzidas a partir de um gesto de abstração que visa deduzir circunstâncias, fixá-las para utilizá-las como modelo para ações futuras. O gesto da nova imaginação não é mais a abstração, seu gesto concretiza, "reúne elementos adimensionais para recolhê-los em uma superfície, ignorando o intervalo entre os pontos" (FLUSSER, 2013: 172). Esse gesto concretiza e projeta uma ideia, nova. As novas imagens são produzidas "para que se busque, além das possibilidades dadas, o inesperado.” (FLUSSER, 2013: 174).

\section{REFERÊNCIAS BIBLIOGRÁFICAS}

FLUSSER, V. O mundo codificado: Por uma filosofia do design e da comunicação. São Paulo: Cosac \& Naif, 2013.

Artigo submetido: 17/04/2015

Artigo aprovado: 22/10/2015 